\title{
KETERLAKSANAAN KOMPETENSI PROFESIONAL \& PEDAGOGIK MAHASISWA PPL DI JURUSAN PENDIDIKAN MIPA UNIVERSITAS CENDERAWASIH
}

\author{
Dolfina C Koirewoa $^{1)}$; Edoward K Raunsay ${ }^{2)}$ \\ ${ }^{1}$ Program Studi Pendidikan Kimia FKIP UNCEN; cleoxa02@gmail.com \\ ${ }^{2}$ Program Studi Pendidikan Biologi FKIP UNCEN; edowardraunsay@ gmail.com
}

\begin{abstract}
This study aims to provide information about the application of professional competence and pedagogical competence of students in the Department of Science education at the Faculty of teacher training and education at Cenderawasih University. This research is an evaluative study by applying a combination method (mixed method) between quantitative and qualitative data obtained through observation and assessment sheet documents (RPP 1 to 10). The results of this study indicate that the professional and pedagogical competencies have been owned by respondents (PPL students) but each competency has not been fully implemented by PPL students. The results of the analysis show that students who apply professional competence are only 44\% or around 19 respondents out of 43 respondents while only pedagogical competencies are $51 \%$ or around 22 respondents.
\end{abstract}

Keywords: professional competence; pedagogical competence; PPL students

\begin{abstract}
ABSTRAK
Penelitian ini bertujuan untuk memberikan informasi tentang penerapan kompetensi profesional dan kompetensi pedagogis mahasiswa dalam pendidikan ilmu Departement di Fakultas pelatihan guru dan pendidikan Universitas Cenderawasih. Penelitian ini adalah penelitian evaluatif dengan menerapkan metode kombinasi (metode campuran) antara data kuantitatif dan kualitatif yang diperoleh melalui observasi dan dokumen penilaian lembar (RPP 1 sampai 10). Hasil penelitian ini menunjukkan bahwa kompetensi profesional dan pedagogik telah dimiliki oleh responden (mahasiswa PPL) tetapi masingmasing kompetensi belum sepenuhnya diimplementasikan oleh mahasiswa PPL. Hasil analisis menunjukkan bahwa siswa yang menerapkan kompetensi profesional hanya 44\% atau sekitar 19 responden dari 43 responden sementara hanya pedagogik kompetensi $51 \%$ atau sekitar 22 responden.
\end{abstract}

Kata kunci: kompetensi professional; kompetensi pedagogik; mahasiswa PPL

\section{PENDAHULUAN}

$$
\text { Lembaga Pendidikan Tenaga }
$$

Kependidikan (LPTK) memiliki mata

kuliah wajib yang harus diikuti oleh seluruh mahasiswa salah satunya yaitu matakuliah Program Pengalaman Lapangan (PPL). Mata kuliah PPL merupakan matakuliah yang bertujuan memberikan ruang atau kesempatan kepada mahasiswa agar memiliki pengalaman yang real atau nyata tentang sekolah dan aktivitas sekolah seperti proses pembelajaran, administrasi dan kegiatan kurikuler \& ekstrakurikuler serta lain 
sebagainya. Hal ini sesuai dengan peryataan bahwa hakikat PPL sangat berorientasi pada kompetensi berbasis pengalaman, membentuk kemampuan professional mahasiswa (calon guru), serta PPL dilaksanakan dan dikelola secara terbimbing dan terpadu (Hamalik, 2010, pp. 170-171).Artinya, matakuliah PPL bertujuan mempersiapkan mahasiswa sebagai calon guru dalam memenuhi persyaratan pembentukan profesi kependidikan melalui pembinaan dan pelatihan kompetensi professional dan pedagogik. PPL dilaksanakan bagi mahasiswa (calon guru) yang secara akademik telah mengikuti sejumlah matakuliah khususnya rumpun keilmuan dan keterampilan (MKKK) dan perilaku berkarya (MKPB) dengan nilai matakuliah microteaching minimal B. Artinya PPL terpadu dalam keseluruhan program pendidikan di LPTK karena pelaksanaan PPL oleh mahasiswa ditunjang oleh setiap matakuliah baik kependidikan maupun keilmuan (Fisika, Biologi dan Kimia). Keterlaksanaan PPL memberikan Pengalaman nyata bagi mahasiswa sehingga mahasiswa PPL memperoleh tambahan pengetahuan atau informasih tentang dunia Pendidikan di luar kampus. Selain itu, matakuliah PPL menjadi ajang atau kesempatan bagi mahasiswa PPL (calon guru) untuk mendemonstrasikan kompetensi yang dibutuhkan bagi seorang pendidik (guru).
Pelaksanaan PPL mencakup latihan mengajar dan tugas-tugas kependidikan diluar mengajar secara terbimbing dan terpadu untuk memenuhi persyaratan pembentukan profesi kependidikan (Hamalik, 2010, pp. 171-172). Pelaksanaan PPL menuntut kemampuan mengajar mahasiswa dalam menerapkan pembelajaran dan penilaian berdasarkan kurikulum yang berlaku. Selain itu, keterlaksanaan PPL selanjutnya berfungsi mempersiapkan seorang mahasiswa (calon guru) untuk memiliki kompetensi dasar sebagai bagian dari tuntutan peningkatan kualitas pendidikan salah satunya dibutuhkan guru yang profesional.Kompetensidasar guru yang dimaksudyaitu, kompetensi professional, pedagogik, social dan Pribadi (Permendiknas, 2007, p. 5; Tandipada, 2016).

Kompetensi dasar guru yang dapat diperoleh melalui berbagai matakuliah kependidikan dan rumpun ilmu antara lain kompetensi professional dan pedagogik. Kompetensi profesional merupakan kemampuan yang harus dimiliki oleh seorang guru berkaitan dengan mata pelajaran yang diajarkannya sedangkan kompetensi pedagogik dapat dipahami sebagai kemampuan seorang guru dalam mengelola kegiatan pembelajaran (Permendiknas, 2007; Koirewoa, 2018). Adapun kompetensi inti yang diharapkan 
dari kompetensi professional dan pedagogik (Tabel 1).

Tabel1: Kompetensi Inti \& Indikator dari

Kompetensi professional dan pedagogik Guru

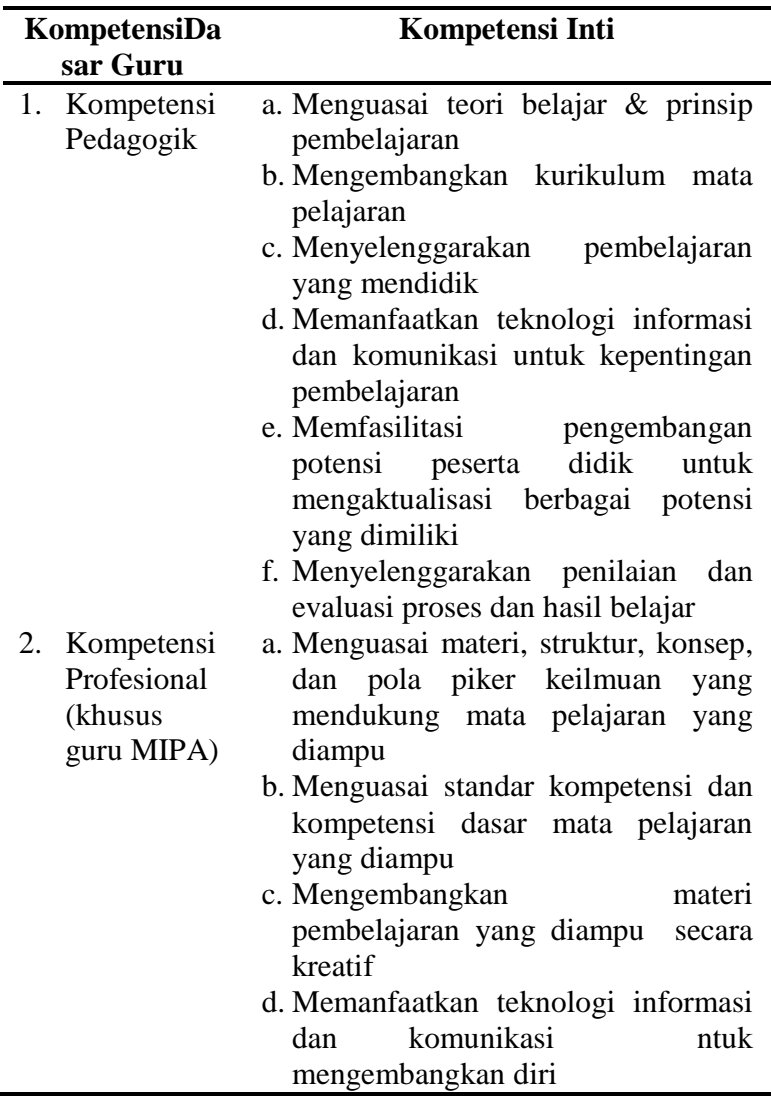

Urgensi penelitian ini memberikan informasi keterlibatan tanggungjawab LPTK dalam menghasilkan calon guru IPA (Fisika, Biologi dan Kimia) yang telah memiliki kompetensi profesional dan pedagogik. Berdasarkan beberapa alasan di atas,maka perlu diadakan evaluasi terhadap kompetensi profesional dan pedagogik yang telah dimiliki oleh mahasiswa di jurusan Pendidikan MIPA FKIP Universitas Cenderawasih selama melaksanakan PPL.

\section{METODE PENELITIAN}

Metode dalam penelitian adalah metode campuran atau kombinasi (mix methode), dengan variasi campuran atau kombinasi bobot tidak sama (dominant status). Kombinasi bobot yang dimaksud yaitu kombinasi jenis data kuantitatif lebih dominan dibanding data kualitatif. Dominasi data kuantitatif dengan cara menambahkan data sekunder (data kualitatif) yang berperan sebagai data pendukung ke dalam data primer (data kuantitatif) sebagai data utama (Ary, Jacob, \& Sorensen, C, 2010)

Subyek dalam penelitian ini adalah mahasiswa di jurusan Pendidikan MIPA (P. Fisika, P. Biologi dan P. Kimia) Universitas Cenderawasih dengan obyek penelitiannya adalah mahasiswa yang mengontrak mata kuliah PPL atau sedang melaksanakan PPL.

Penelitian ini menggunakan teknik non-sampling yaitu purposive sampling dengan pertimbangan bahwa obyek penelitian adalah mahasiswa pendidikan IPA (Fisika, Biologi dan Kimia) yang secara akademik dan administrasi, dinyatakan dapat mengikuti PPL di jurusan Pendidikan MIPA. Jenis penelitian ini menerapkan model evaluasi kesenjangan (discrepancy model)(Wirawan, 2012, hal. 58; Hasanah, 2017)

Variabel penelitian pada penelitian ini yaitu keterlaksanaan kompetensi profesional dan pedagogik mahasiswa selama melaksanakan PPL. Variabel 
penelitian tersebut di definisikan secara operasional sebagai berikut:

a. Kompetensi profesional: kemampuan mahasiswa PPL dalam penguasaan materi pelajaran (Fisika, Biologi dan Kimia) yang diampu dalam setiap pembelajaran.

b. Kompetensi pedagogik: kemampuan mahasiswa PPL dalam mendemonstrasikan melaksanakan setiap pembelajaran (RPP 1 samapai RPP 10).

Teknik \& Instrumen Pengumpulan Data

a. Teknik Pengumpulan Data

Teknik pengumpulan data dalam penelitian ini didasarkan pada kebutuhan informasi yang telah didefinisikan secara operasional (variabel peneliltian) dan mempertimbangkan metode penelitian yang diterapkan oleh peneliti. Adapun teknik pengumpulan data yang digunakan dalam penelitian ini yaitu dokumentasi dan observasi (Fraenkel \& Wallen, 2007; Lungan, 2006; McMilan $\&$ Schumacher, 2001).

b. Instrumen Pengumpulan Data

Informasi atau data yang dibutuhkan oleh peneliti, dikumpulkan dengan alat ukur yang disebut dengan instrumen (Djaali \& Muljono, 2008; Sanjaya, 2014). Adapun instrument yang digunakan yaitu:
1) Lembar Observasi, untuk memperoleh informasi kompetensi pedagogik melalui performa mahasiswa PPL selama melaksanakan proses pembelajaran (RPP1 sampai RPP10)

2) Lembar Penilaian Dokumen, untuk mengumpulkan informasi penguasaan materi pelajaran (Fisika, Biologi dan Kimia) dari setiap mahasiswa PPL.

Teknik Analisis Data

Sesuai dengan pendekatan dan jenis data yang terkumpul melalui instrumen penelitian (lembar observasi penilaian dokumen) maka teknik analisis data yang digunakan dalam penelitian ini adalah analisis statistik deskriptif kuantitatif.

Hasil penelitian diinterpretasikan menggunakan kriteria atau kategori tertentu (Tabel 2). Kategorisasi didasarkan pada prinsip distribusi normal sesuai dengan jenis instrument yang digunakan (Mardapi, 2012). Teknik analisis data yang digunakan dalam penelitian ini adalah triangulasi data.

Tabel 2. Kategori Skor

\begin{tabular}{|c|c|}
\hline Skor Mahasiswa & Kategori \\
\hline$X \geq \bar{x}+1$. SD $_{\mathbf{x}}$ & Sangat tinggi \\
\hline $\bar{x}+\mathbf{1 . S D _ { \mathbf { x } }}>X \geq \bar{x}$ & Tinggi \\
\hline $\bar{x}>X \geq \bar{x}-$ 1.SD $_{\mathbf{x}}$ & Kurang Tinggi \\
\hline$X<x-1 . \mathrm{SD}_{\mathrm{x}}$ & Rendah \\
\hline $\begin{array}{l}\text { Keterangan: } X \text { menyat } \\
\text { menyatakan } \\
\text { dan } \operatorname{SD}_{\mathrm{x}} \\
\text { Skor }\end{array}$ & $\begin{array}{l}\text { or Pengukuran, } x \\
\text { Skor Pengukuran } \\
\text { n Standar Deviasi }\end{array}$ \\
\hline
\end{tabular}




\section{HASIL DAN PEMBAHASAN}

Data pengukuran yang dilakukan terhadap kompetensi profesional dan pedagogik mahasiswa PPL di jurusan Pendidikan MIPA melalui instrument penelitian dapat dilihat pada Gambar 1.

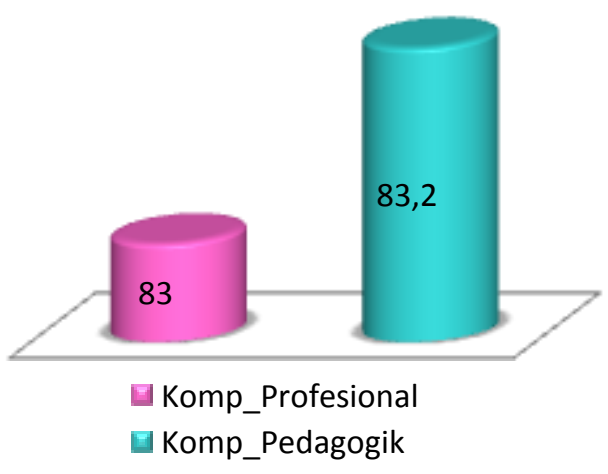

Gambar 1. Rata-rata Kompetensi Profesional \& Pedagogik Mahasiswa PPL di Jurusan

P.MIPA

Berdasarkan Gambar 1 menunjukkan bahwa kompetensi pedagogik 83,2 \% dan kompetensi profesional $83 \%$. Data pengukuran yang diperoleh melalui instrumen penelitian dianalisis menggunakan statistik deskriptif untuk kompetensi professional dan pedagogik pada Tabel 3, sehingga diperoleh kategorisasi untuk masing masing kompetensi.

Tabel 3:.Analisis Deskriptif Kompetensi

Profesional \& Pedagogik Mahasiswa PPL

\begin{tabular}{lcccccc}
\hline & N & R & Min & Max & Mean & SD \\
\hline K_Prof & 43 & 20.70 & 72.70 & 93.40 & 83.0023 & 4.39927 \\
K_Ped & 43 & 17.41 & 74.29 & 91.70 & 83.1834 & 4.24112 \\
\hline
\end{tabular}

Hasil analisis deskriptif dari setiap kompetensi menjadi dasar bagi peneliti untuk melakukan kategorisasi (Tabel.3). Kategorisasi dilakukan untuk setiap kompetensi pada subyek penelitian (responden), sehingga diperoleh persentase untuk setiap kategori untuk masing masing kompetensi (Gambar 2 dan 3).

Hasil kategorisasi (Gambar 2) menunjukkan bahwa keterlaksanaan kompetensi profesional oleh mahasiswa PPL di Jurusan P. MIPA hanya sebesar 44\% (16\% Sangat Tinggi\& 28\% Tinggi). Hasil 44\% menunjukkan bahwa sebanyak 19 responden (mahasiswa PPL) mampu menerapkan kompetensi profesional. Hasil tersebut menunjukkan bahwa dari 43 responden yang mengikuti PPL hanya 19 responden yang mampu melaksanakan atau menunjukkan kompetensi profesional. Sementara sebanyak $56 \%$ (49\% Kurang Tinggi \& 7\% Rendah) masih kurang mampu melaksanakan kompetensi Profesional. Artinya, sebagian besar mahasiswa PPLmasih kurang dalam penguasaan materi, struktur, konsep, dan pola pikir keilmuan (Fisika, Kimia dan Biologi).

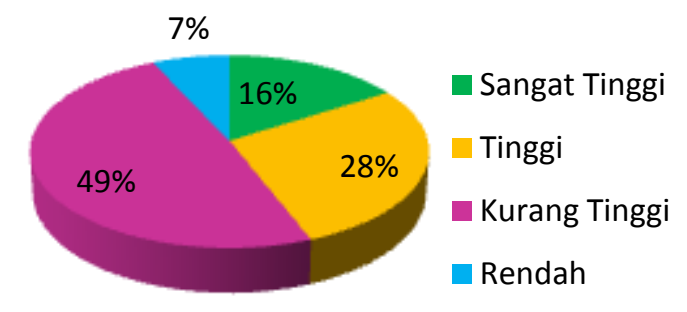

Gambar2: Persentase Kategori dari KompetensiProfesional 
Data yang ditampilkan pada Gambar 3 menunjukkan bahwa keterlaksanaan kompetensi pedagogik oleh mahasiswa PPL di Jurusan P. MIPA sebesar 51\% (14\% Sangat Tinggi\& 37\% Tinggi). Sementara masih ada sebanyak 49 $\%$ (33\% Kurang Tinggi \& $16 \%$ Rendah) responden yang kurang mampu melaksanakan kompetensi pedagogik.

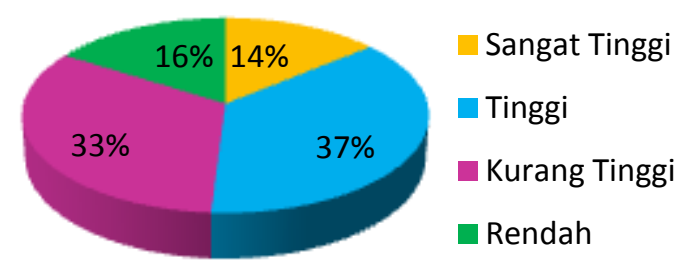

Gambar3 : Persentase Kategoridari Kompetensi Pedagogik

Persentase $51 \%$ menunjukkan bahwa sebanyak 22 responden (mahasiswa PPL) mampu menerapkan kompetensi pedagogik selama melaksanakan PPL.Dari diagram tersebut (Gambar 3) menunjukkan bahwa sebagian besar mahasiswa PPL (22 dari 43 responden) telah memiliki dan mampu menerapkan teori belajar dan prinsipprinsip pembelajaran yang mendidik, mengembangkan kurikulum mata pelajaran, menyelenggarakan pembelajaran yang mendidik, memanfaatkan teknologi informasi dan komunikasi untuk kepentingan pembelajaran, memfasilitasi pengembangan potensi peserta didik untuk mengaktualisasi berbagai potensi yang dimiliki, menyelenggara penilaian dan melakukan evaluasi proses dan hasil belajar. Keterlaksanaan kompetensi pedagogik ini berpengaruh positif terhadap hasil belajar peserta didik (Tandipada, 2016, hal. 47).

\section{SIMPULAN DAN SARAN \\ SIMPULAN}

Kompetensi profesional dan pedagogik umumnya terlaksana masing masing sebesar $44 \%$ dan $51 \%$, oleh mahasiswa PPL di jurusan P.MIPA FKIP UNCEN.

\section{SARAN}

Adapun saran bagi para peneliti lainnya yaitu perlu ada kajian lanjutan yang meliputi setiap sub indikator dari masing - masing kompetensi.

\section{UCAPAN TERIMA KASIH}

Penulis mengucapkan terima kasih kepada Ketua Lembaga Penelitian dan Pengabdian Kepada Masyarakat (LPPM) Universitas Cenderawasih JAyapura atas dukungan pendanaan PNBP yang dibiayai dari PNBP LPPM UNCEN, Tim Redaksi Jurnal Ilmu Pendidikan Indonesia yang telah menerima artikel ini dan kepada seluruh Mahasiswa PPL di Jurusan Pendidikan MIPA FKIP UNCEN.

\section{DAFTAR PUSTAKA}

Ary, D., Jacob, L., \& Sorensen, C. (2010). Introduction to research in Education. Belmont: Wadsworth, Cengage Learning; 
Djaali, H., \& Muljono, P. (2008). Pengukuran Dalam Bidang Pendidikan. Jakarta: Grasindo;

Fraenkel, J. R., \& Wallen, N. E. (2007). How To Design and Evaluate Research in Education (6 ed.). New York: McGraw-Hill;

Hamalik, O. (2010). Manajemen Pengembangan Kurikulum. Bandung: PT. Rosdakarya;

Hasanah, U. N. (2017). Evaluasi Implementasi Kurikulum 2013 Pada SMA Pilot Project Di Kota Yogyakarta. Jurnal Akuntabilitas Manajemen Pendidikan, 5, 95 108 ;

Koirewoa, D. C. (2018). Kompetensi Pedagogik Mahasiswa Program Pengalaman Lapangan Dalam Pembelajaran Kimia Melalui Scientific Approach. Jurnal Ilmu Pendidikan Indonesia, 6, 1-7;

Lungan. (2006). Aplikasi Statistik \& Hitung Peluang. Yogyakarta: Graha Ilmu;

Mardapi, D. (2012). Pengukuran, Penilaian dan Evaluasi Pendidikan. Yogyakarta: Nuha Medika;

McMilan, J. H., \& Schumacher, S. (2001). Research In Education a Conseptual Introduction (5 ed.). Virginia: Addison Wesley Longaman;

Permendiknas. (2007). Peraturan Menteri Pendidikan Nasional republik Indonesia Nomor 16 Tahuin 2007 Tentang Standar Kualifikasi dan Kompetensi Guru;
Sanjaya, W. (2014). Penelitian Pendidikan (Jenis Metode \& Prosedur) . Jakarta: Kencana Prenada Media Group;

Tandipada, Y. (2016). Pengaruh Kompetensi Pedagogik dan Motivasi Kinerja Guru IPA Terhadap Hasil Belajar Pada Materi Fotosintesis Siswa Kelas VIII SMP Negeri 1 Dekai. Jurnal Ilmu Pendidikan Indonesia, 4, 37-48;

Wirawan. (2012). Evaluasi (Teori, Model, Standar, Aplikasi dan Profesi) (2 ed.). Jakarta: Rajawali Pers. 